\title{
Design of TID controller based on firefly algorithm for controlling the speed of a D.C. Motor
} \author{
Tirumalasetty Chiranjeevi ${ }^{3}$ \\ ${ }^{1}$ B.Tech student, EE Department, REC Sonbhadra, Uttar Pradesh, India \\ ${ }^{2} \mathrm{Ph} . \mathrm{D}$ scholar, EE Department, NIT Silchar, Assam, India \\ ${ }^{3}$ Asst. Professor, EE Department, REC Sonbhadra, Uttar Pradesh, India
}

Govind Kumar Rajput ${ }^{l}$, Adesh Yadav ${ }^{1}$, Ajay Kumar ${ }^{l}$, Abhishek Gautam ${ }^{l}$, Anand Tiwari ${ }^{l}$, Naladi Ram Babu ${ }^{2, *}$,

\begin{abstract}
Implementation of tilt integral derivative (TID) controller for controlling the speed of a D.C. Motor using meta heuristic nature inspired algorithm named by firefly algorithm (FA) is proposed in this paper. By using FA based optimization technique, we have tuned TID controller parameters. Further, comparative analysis has been done with FA based conventional PID and fractional order PID (FOPID) controllers. The performance of TID is investigated in terms of various performance indices like integral of square error (ISE), integral of time-weighted absolute error (ITAE), integral of absolute error (IAE) and integral of time-weighted square error (ITSE). Investigation carried out reveals the advantage of TID over conventional PID and FOPID in terms of reduced settling time and performance indices.
\end{abstract}

\section{Introduction}

Fractional calculus $(\mathrm{FC})$ is a division of mathematics that deals with the fractional order (FO) integrals and derivatives. It is the generalization of integer order calculus. This subject is initiated over 300 years ago. Many great mathematicians contributed in this subject from last few decades. In olden days most of the researchers except mathematicians, are not aware of this subject.

During 300 years, FC has developed as a pure theoretical field of mathematics. From the last few decades scenario has been changed. Most of the researchers from different fields are paying attention on FO systems because, the system modeling considering FO differential equations provides more accurate results compared with the integer order systems [1-16]. Most of the scientists and engineers from the last few years adopted $\mathrm{FC}$ in various areas of science and engineering [1-16].

Controlling the speed of a D.C. Motor is very important because D.C. Motors having wide applications in industry and commercial point of view [17]. For controlling the speed of a D.C. Motor, So many integer order PID controller designs are available in literature but very few works available in literature related to FOPID controllers by using various optimization algorithms like Genetic Algorithm [17-20], Cuckoo search [21], Bee Colony optimization technique [22-23], Grey Wolf optimization technique [24]. In [25], ANFIS based FOPID controller and in [26] FOPID controller grounded on stability boundary method have been implemented for controlling the speed of a D.C. Motor.
In this paper, TID controller is designed for speed control of D.C. Motor. The parameters of the TID controller have been tuned by using FA. Later comparative analysis has been made with FA based conventional PID and FOPID in the sense of settling time. Thereafter, TID controller performance has been investigated in terms of various performance indices like ISE, ITAE, ITSE and IAE.

\section{System under investigation}

In this work we have considered MS 15 D.C. Servo Motor for investigation and it is shown in Fig.1. The motors angular velocity is regulated by the constant supply voltage (Va) i.e., plant's input. Va provides constant torque and helps in attaining constant speed which is measured by the tacho-generator placed on motors shaft. The tacho-generator produces the plant's output voltage which is proportional to the motors speed and it acts a plant's feedback. The plant transfer function is given by [17]

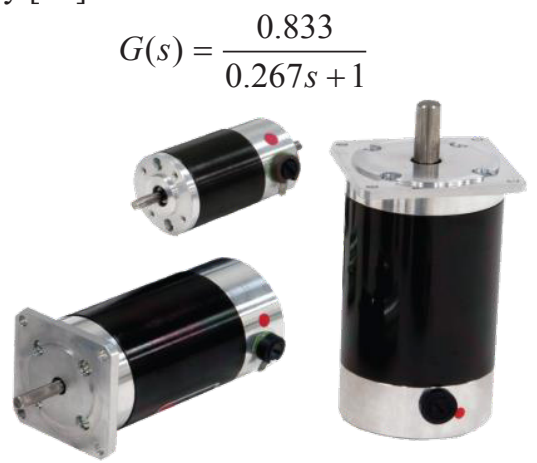

\footnotetext{
* Corresponding author: ram1992babu $@$ gmail.com
} 


\section{TID controller}

TID's design is similar to PID but the modification is that PID's proportional constant is replaced by " $(1 / \mathrm{s})^{\mathrm{n}}$ " with real number (n). The equations of PID, FOPID and TID are given by. (2) - (4).

$$
\begin{gathered}
\left.T F\right|_{P I D}=K_{P}+\frac{K_{I}}{s}+K_{D} s \\
\left.T F\right|_{F O P I D}=K_{P}+\frac{K_{I}}{s^{\lambda}}+K_{D} s^{\mu} \\
\left.T F\right|_{T I D}=K_{T}\left(\frac{1}{s}\right)^{n}+\frac{K_{I}}{s}+K_{D^{S}}
\end{gathered}
$$

$\mathrm{K}_{\mathrm{P}} / \mathrm{K}_{\mathrm{T}}, \mathrm{K}_{\mathrm{D}}$ and $\mathrm{K}_{\mathrm{I}}$ are proportional/tilt, integral and derivative constants of controllers. From Eqs. (2) and (4) we can say that TID is a combination of FO and integer controllers. TID has an advantage of both integer and FO controllers. It achieves quick disturbance elimination among integer and FO controllers. The TID values are enhanced by FA with constraints in Eq. (5) considering various performance indices and its structure is illustrated in Fig.2.

$$
0 \leq K_{T} \leq 1,0 \leq K_{I} \leq 1,0 \leq K_{D} \leq 1 \text { and } 1 \leq n \leq 7
$$

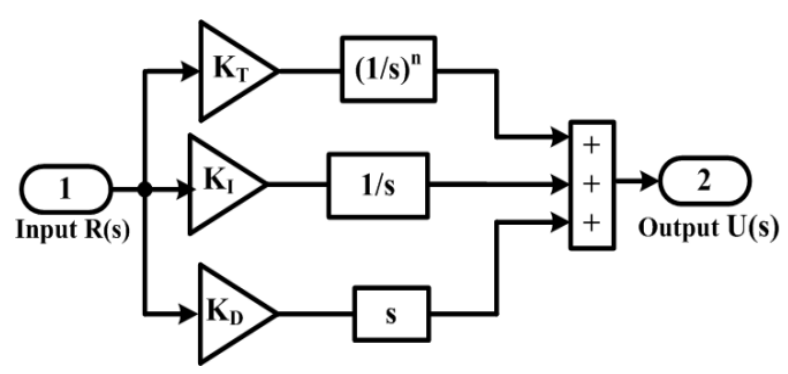

Fig. 2. TID controller.

\section{Firefly algorithm}

FA was developed by Yang in 2008. It works on the fireflies brightness. The characteristics of FA are (a) Firefly attracts each other's depending on brightness, (b) Higher brightness firefly has high attraction level and (c) Lower brightness firefly tends toward higher brightness firefly.

The firefly attractiveness depends on the distance between them and its expression is given by

$$
I(r)=\frac{I_{s}}{r^{2}}
$$

where source brightness $\left(\mathrm{I}_{\mathrm{s}}\right)$, brightness (I) and distance (r). The firefly brightness in a constant light coefficient $(\gamma)$ medium is given by $(6)$

$$
I_{s}=I_{0} e^{-\lambda r}
$$

where $I_{0}$ is unique brightness. The attractiveness of firefly seen by the next firefly can be defined by

$$
\beta=\beta_{0} e^{-\lambda r^{2}}
$$

whereis $\beta_{0}$ attractiveness at $\mathrm{r}=0$. Based on its brightness (objective function) the fireflies with lower brightness mates with fireflies of higher brightness in order to produce new solutions. Therefore, in FA previous solution is updated by a new solution based on their brightness level and its Flow chart of FA is illustrated in Fig. 3. The best solution is considered with good fitness. The tuned values of FA are fireflies number $=30$, $\max _{\text {gen }}$ $=100, \beta=0.3, \alpha=0.4$ and $\gamma=0.6$.

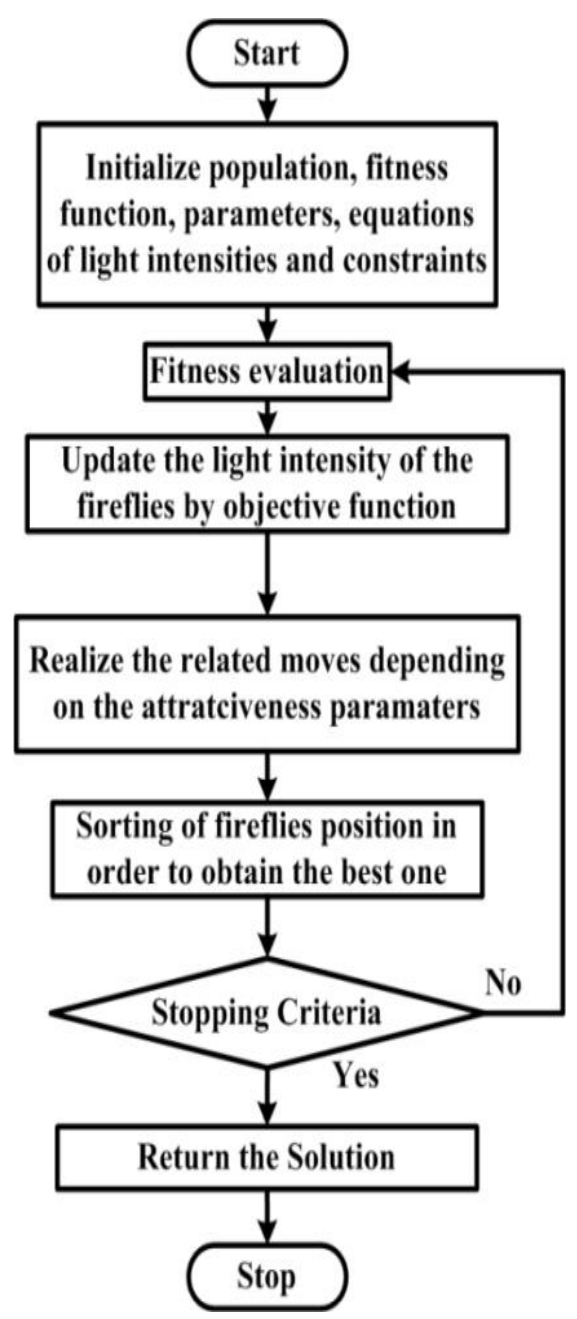

Fig. 3. Flow chart of FA.

\section{Results and discussion}

\subsection{Controller comparison among PID, FOPID and TID}

The transfer function model in fig.4 is taken for investigations. It is given different controllers like FOPID, PID and the proposed TID controller. FA optimizes the controller gains considering ISE as performance indices. The figures corresponding to optimum values in Table-1 are plotted in Fig. 5 - Fig. 7 and compared in Fig.8. Careful investigations of Fig.8 and Table.2 suggests that the TID controller shows improved response over others in terms of settling time. 

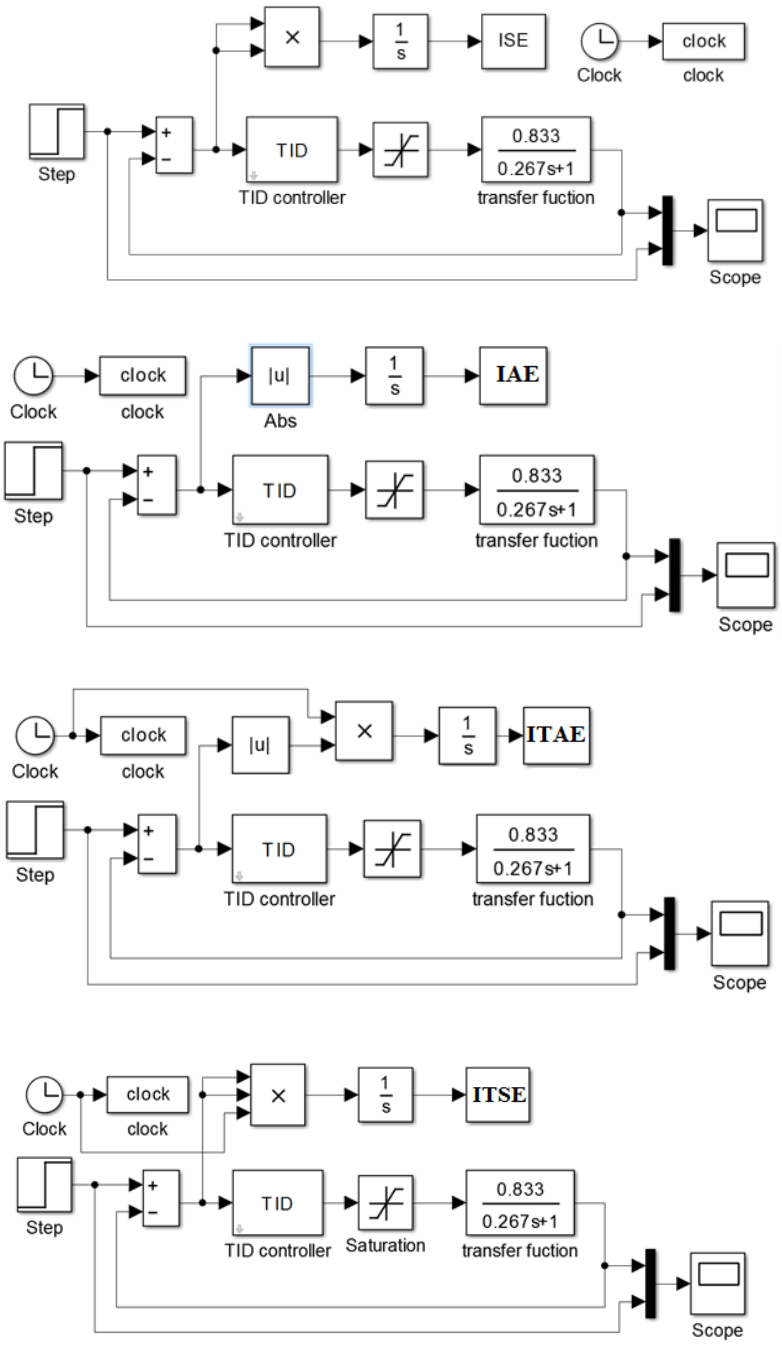

Fig. 4. Simulink models for D.C. Motor speed control using TID controller.

Table 1. Optimum controller parameters considering FA.

\begin{tabular}{|l|l|}
\hline PID & $\begin{array}{l}\mathrm{KP}=0.3836, \mathrm{KI}=0.9815, \mathrm{KD}=0.3037, \\
\mathrm{~N}=91.2881\end{array}$ \\
\hline FOPID & $\begin{array}{l}\mathrm{KP}=0.3845, \mathrm{KI}=0.9784, \text { lambda }=0.9989, \\
\mathrm{KD}=0.3784, \mathrm{mu}=0.1548\end{array}$ \\
\hline & \multicolumn{2}{|c|}{\begin{tabular}{l}
$\mathrm{KT}=0.3246, \mathrm{KI}=0.8810, \mathrm{KD}=0.3147, \mathrm{n}=6.749$ \\
\hline
\end{tabular}} \\
\hline
\end{tabular}

Table 2. Settling time comparison among various controllers.

\begin{tabular}{|l|l|l|l|}
\hline Settling time & $\mathrm{PID}=8 \mathrm{~s}$ & $\mathrm{FOPID}=7 \mathrm{~s}$ & $\mathrm{TID}=4 \mathrm{~s}$ \\
\hline
\end{tabular}

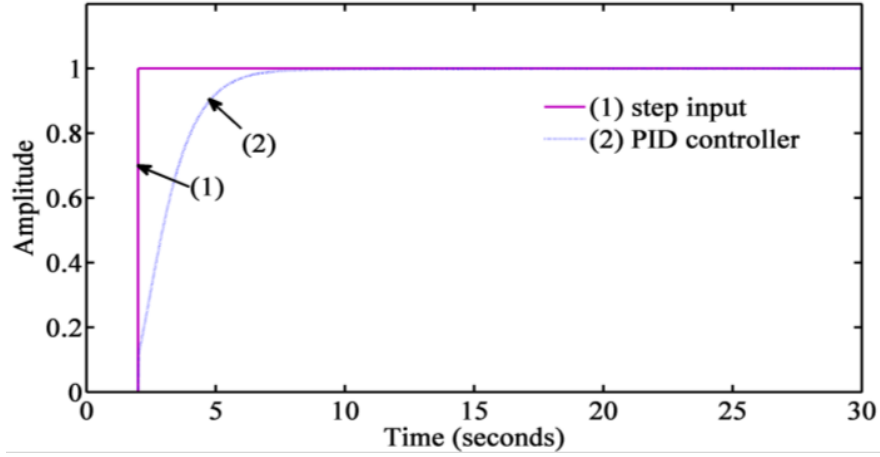

Fig. 5. Response with PID controller.

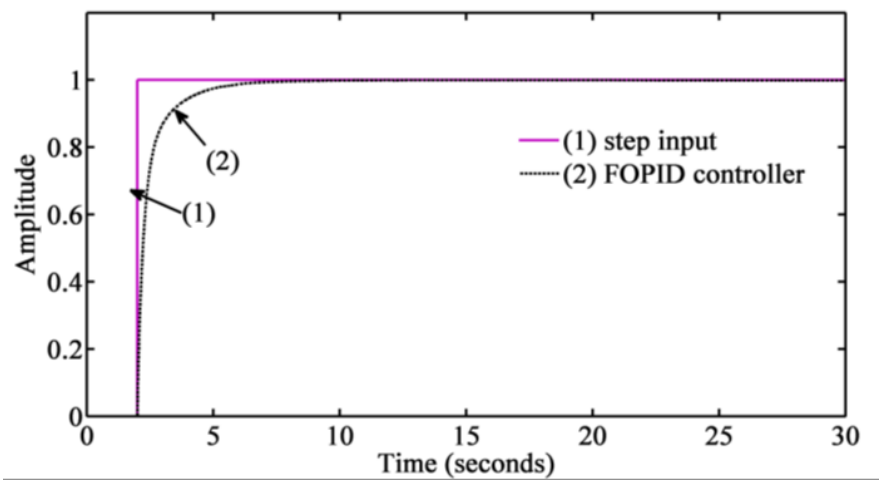

Fig. 6. Response with FOPID controller.

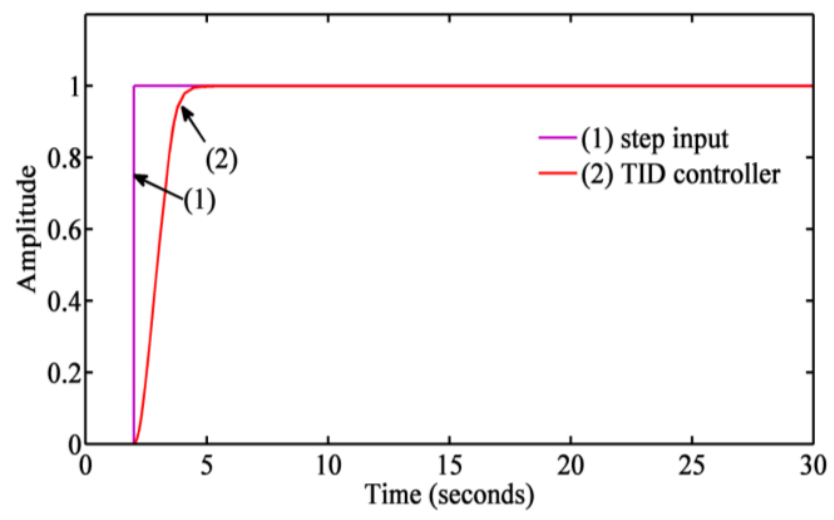

Fig. 7. Response with TID controller.

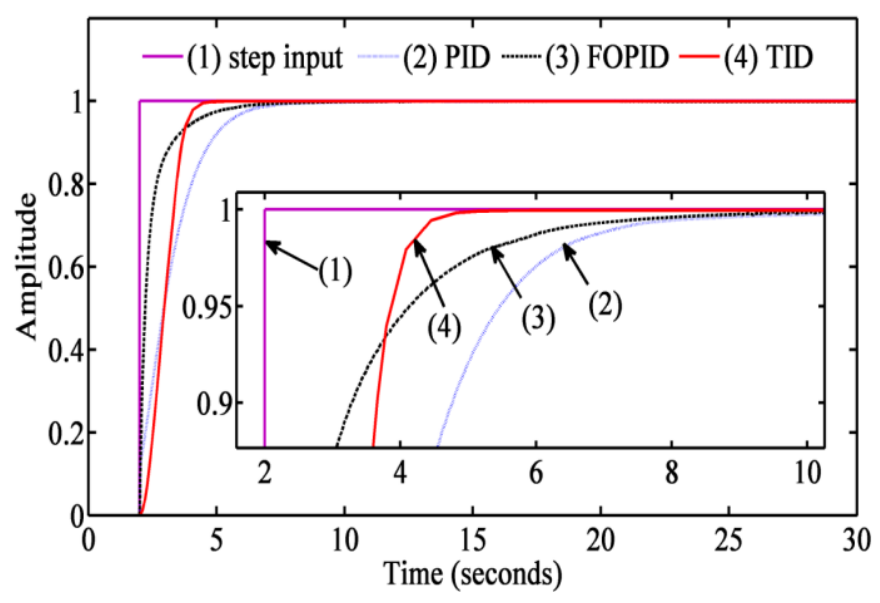

Fig. 8. Comparison of system response with FOPID, PID and TID 


\subsection{System response comparison with various performance index criteria}

The transfer function model in Fig.4 are considered. They are provided with the best controller obtained from above case study. The TID controller gains are augmented by FA with numerous performance indices such as ISE, IAE, ITSE and ITAE. The system responses corresponding to various performance indices are compared and are plotted. Critical observations reveal that the performance indices of TID show better response over other two controllers.

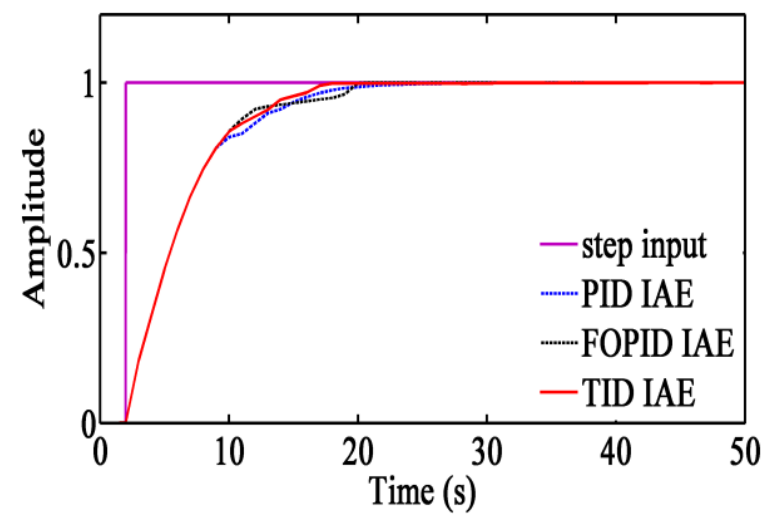

Fig. 9. Comparison of IAE with FOPID, PID and TID.

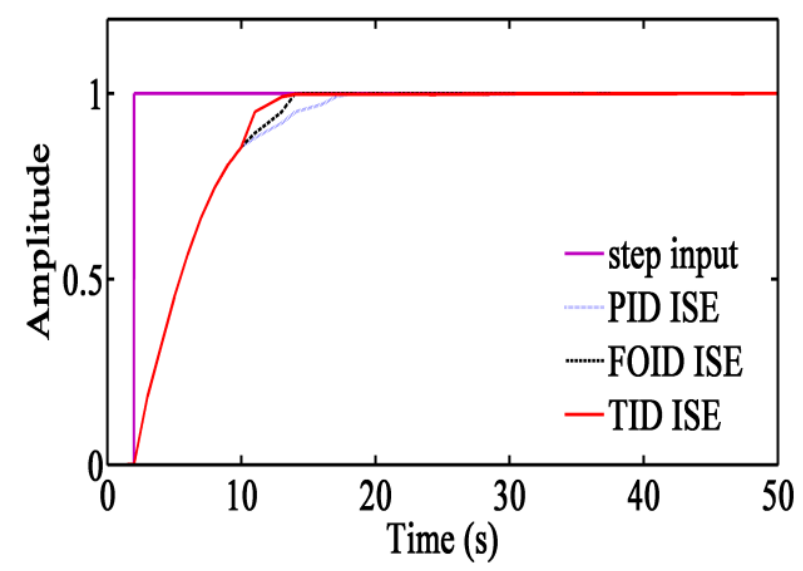

Fig. 10. Comparison of ISE with FOPID, PID and TID.

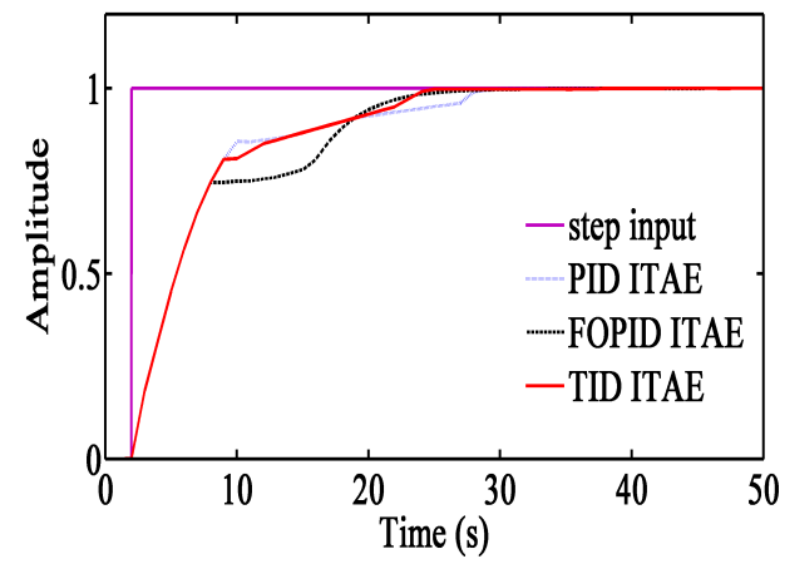

Fig. 11. Comparison of ITAE with FOPID, PID and TID.

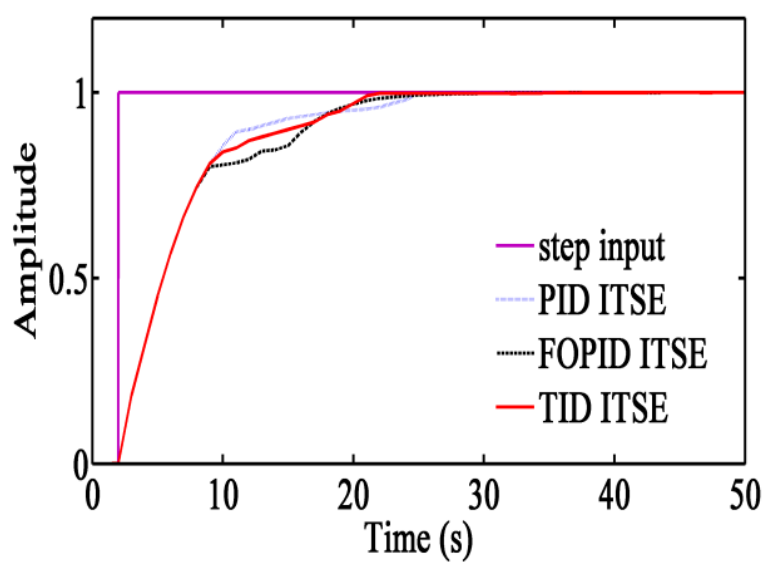

Fig. 12. Comparison of ITSE with FOPID, PID and TID.

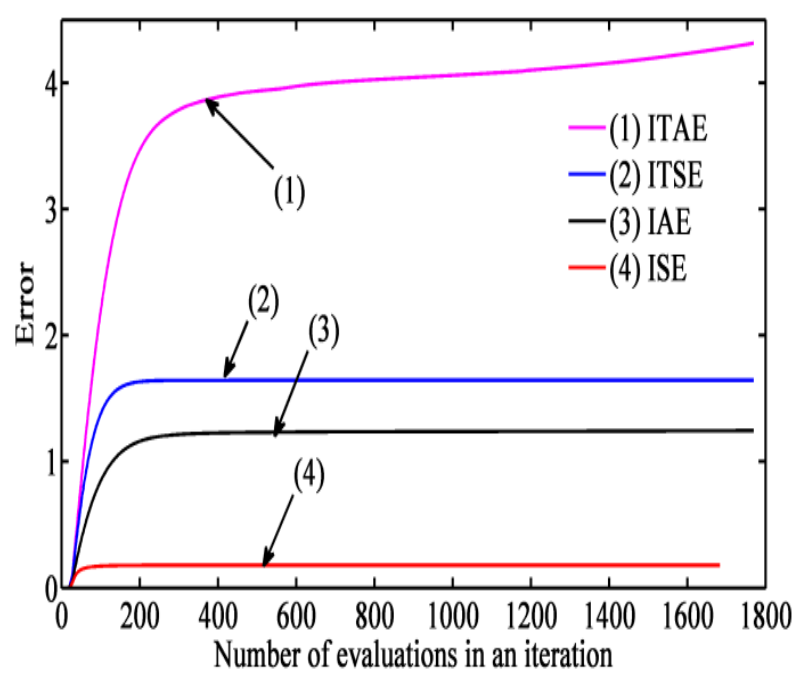

Fig. 13. Performance index comparison with TID.

\section{Conclusion}

For controlling the speed of a D.C. Motor, In this work we have proposed TID controller design by using meta heuristic nature inspired algorithm named by FA. We have tuned TID controller parameters by using FA based optimization technique. Later, comparative analysis has been made with FA based integer order PID and FOPID controllers. In the sense of various performance indices like ITSE, ISE, ITAE, IAE, the performance of TID is investigated and it shows that the ISE show better results over other indices. Investigation accomplished acknowledges the advantage of TID over conventional PID and FOPID in terms of reduced settling time. In future, we would like to implement the proposed work on hardware.

\section{References}

1. I. Podlubny, Fractional differential equations (Academic Press, New York, 1999).

2. T. Chiranjeevi, R. K. Biswas, Mathematics 5, 1 (2017). 
3. A. Dzielinski, D. Sierociuk, G. Sarwas, Bull. Pol. Ac.: Tech. 58, 583 (2010).

4. T. Chiranjeevi, R. K. Biswas, J. King Saud Univ. Sci. 31, 1042 (2019).

5. N. R. Babu, V. Narrisetty, L. C. Saikia, 2019 IEEE 16th India Council International Conference (INDICON), 1 (2019).

6. G. Suri babu, T. Chiranjeevi, IFAC Papers Online 49, 456 (2016).

7. N. R. Babu, L. C. Saikia, IET Renewable Power Generation 13, 2221 (2019).

8. T. Chiranjeevi, R. K. Biswas, Chudamani Sethi, Int. J.Electr. Eng. Educ., 1 (2019). doi: 10.1177/0020720919833031.

9. T. Chiranjeevi, R. K. Biswas, Procedia Computer Science 171, 1261 (2020).

10. T. Chiranjeevi, R. K. Biswas, N. Rambabu, J. Interdiscip. Math. 23, 293 (2020).

11. N. R. Babu, L. C. Saikia, International Transactions on Electrical Energy Systems 30, 1 (2020).

12. T. Chiranjeevi, R. K. Biswas, Procedia Computer Science 171, 2030 (2020).

13. T. Chiranjeevi, R. K. Biswas, Journal of Advanced Research in Dynamical and Control Systems 10, 201 (2018).

14. D. Sierociuk, T. Skovranek, M. Macias, I. Podlubny, I. Petras, A. Dzielinski, P. Ziubinski, Appl. Math. Comput. 257, 2 (2015).

15. T. Chiranjeevi, R. K. Biswas, S. K. Pandey, Computing Algorithms with Applications in Engineering, 285 (2020).

16. N. R. Babu, D. K. Sahu, L. C. Saikia, S. K. Ramoji, 2019 IEEE 16th India Council International Conference (INDICON), 1 (2019).

17. V. Mehra, S. Srivastava, P. Varshney, $20103 r d$ International Conference on Emerging Trends in Engineering and Technology, 422 (2010).

18. Suresh Kumar T, Sankar V, 2011 IEEE India Conference, INDICON, 2011.

19. P. Kumar, S. Chatterjee, D. Shah, U. K. Saha, S. Chatterjee, Cogent Engineering 4, 1 (2017).

20. T. Wati, Subiyanto, Sutarno, Journal of Physics: Conference Series 1444, 1 (2020).

21. C. Thammarat, D. Puangdownreong, International Journal Of Circuits, Systems and Signal Processing 13, 92 (2019).

22. I. K. Mohammed, A. I. Abdulla, International Journal of Computer Applications 179, 43 (2018).

23. A. Rajasekhar, S. Das, A. Abraham, 2013 World Congress on Nature and Biologically Inspired Computing, 259 (2013).

24. Srinivasa Rao D, Sandhya Rani MN, Sarfaraz Nawa z Syed and Suresh Kumar Tummala, E3S Web of Conferences 8701003 (2019).

25. K. Balamurugan, R. Mahalakshmi, International Journal of Wavelets, Multiresolution and Information Processing 18, 1 (2020).

26. N. N. Praboo, P. K. Bhaba, International Journal of Engineering Trends and Technology 4, 3403 (2013). 